\title{
Direct Observations of Oxygen-induced Platinum Nanoparticle Ripening Studied by In Situ TEM
}

\author{
Simonsen, Søren Bredmose; Chorkendorff, Ib; Dahl, Søren; Skoglundh, M.; Sehested, J.; Helveg, S.
}

Published in:

Journal of the American Chemical Society

Link to article, DOI:

$10.1021 / j a 910094 r$

Publication date:

2010

Document Version

Peer reviewed version

Link back to DTU Orbit

Citation $(A P A)$ :

Simonsen, S. B., Chorkendorff, I., Dahl, S., Skoglundh, M., Sehested, J., \& Helveg, S. (2010). Direct Observations of Oxygen-induced Platinum Nanoparticle Ripening Studied by In Situ TEM. Journal of the American Chemical Society, 132(23), 7968-7975. https://doi.org/10.1021/ja910094r

\section{General rights}

Copyright and moral rights for the publications made accessible in the public portal are retained by the authors and/or other copyright owners and it is a condition of accessing publications that users recognise and abide by the legal requirements associated with these rights.

- Users may download and print one copy of any publication from the public portal for the purpose of private study or research.

- You may not further distribute the material or use it for any profit-making activity or commercial gain

- You may freely distribute the URL identifying the publication in the public portal 


\title{
Direct observations of oxygen induced platinum
}

\section{nanoparticle ripening studied by in situ TEM}

Søren B. Simonsen ${ }^{a, b}$, Ib Chorkendorff $^{b}$, Søren Dahl ${ }^{b}$, Magnus Skoglundh ${ }^{c}$, Jens Sehested ${ }^{a}$, Stig Helveg $^{a, *}$

\begin{abstract}
${ }^{\mathrm{a}}$ Haldor Topsøe A/S, Nymøllevej 55, DK-2800 Kgs. Lyngby, Denmark, ${ }^{\mathrm{b}}$ CINF, Department of Physics, Technical University of Denmark, DK-2800 Kgs. Lyngby, Denmark, ${ }^{\mathrm{c}}$ Competence Centre for Catalysis (KCK) Chalmers University of Technology, SE-41296, Göteborg, Sweden.
\end{abstract}

*Corresponding author: Stig Helveg, e-mail: sth@topsoe.dk

\section{RECEIVED DATE (to be automatically inserted after your manuscript is accepted if required according to the journal that you are submitting your paper to)}

TITLE RUNNING HEAD: Pt nanoparticle ripening studied by in situ TEM

ABSTRACT: This study addresses the sintering mechanism of Pt nanoparticles dispersed on a planar, amorphous $\mathrm{Al}_{2} \mathrm{O}_{3}$ support as a model system for a catalyst for automotive exhaust abatement. By means of in situ transmission electron microscopy (TEM), the model catalyst is monitored during the exposure to 10 mbar air at $650^{\circ} \mathrm{C}$. Time-resolved image series unequivocally reveal that the sintering of $\mathrm{Pt}$ nanoparticles is mediated by an Ostwald ripening process. A statistical analysis of an ensemble of Pt nanoparticles shows that the particle size distributions change shape from an initial Gaussian distribution via a lognormal distribution to a Lifshitz-Slyozov-Wagner (LSW) distribution. Furthermore, the time-dependency of the ensemble-averaged particle size and particle density is determined. A mean field kinetic description captures the main trends in the observed behavior. However, at the individual 
nanoparticle level, deviations from the model are observed suggesting in part that the local environment influences the atom exchange process.

KEYWORDS: Sintering, Ostwald ripening, nanoparticles, in situ TEM, Pt, catalysis, automotive catalysts

\section{Introduction}

The size and shape of nano-scale structures often play a crucial role for the physiochemical properties of a nanomaterial ${ }^{1,2}$. Although a variety of size-selected nanoparticle synthesis methods are available, the stability of the nanoscale structures is by no means guaranteed. Due to their excess surface free energy, nanoscale structures present a metastable solid state and will inevitably tend to aggregate into larger structures $^{3-6}$. The stability of metal nanoparticles dispersed on for example an oxide support is important for their extensive use as efficient catalysts in environmental technologies and in the production of fuels and chemicals ${ }^{1,2}$. The high temperature and reactive gas conditions encountered during catalysis often accelerate the sintering which results in loss of active surface area of the nanoparticles causing an undesired catalyst deactivation. To further advance the synthesis and application of stable catalysts, and nanostructures in general, a detailed understanding of the mechanisms and kinetics governing their stability is of utmost importance.

The sintering of supported nanoparticles is typically attributed to mass transport mechanisms involving crystallite or atomic migration. The crystallite migration mechanism refers to sintering mediated by the migration of the nanoparticles and subsequent coalescence with neighboring nanoparticles ${ }^{3}$. The atom migration mechanism refers to the Ostwald ripening process in which sintering occurs by diffusion of atoms or atomic species between immobile nanoparticles either on the surface of the support or through the gas phase ${ }^{3,7}$. For both mechanisms, kinetic models for the sintering of the supported nanoparticles have been established ${ }^{3,7}$. Specifically, the Ostwald ripening process is influenced by the so-called Gibbs-Thomson effect relating surface coverage to vapor pressure. The result is here that the concentration of atomic 
species in the vicinity of a particle is higher for small particles than for large particles. This concentration gradient leads to a net flux of atomic species from the smaller particles towards the larger ones, so the larger particles eventually grow at the expense of the smaller ones. A meanfield model for Ostwald ripening kinetics, relevant for the present Pt catalyst described below $^{8}$, describes the so-called interfacecontrolled rate of nanoparticle radius changes, $d R / d t, \mathrm{by}^{3,9}$,

$$
\frac{d R}{d t}=\frac{\alpha}{R^{2}}\left(\frac{R}{R^{*}}-1\right)
$$

where $\alpha$ is a system dependent parameter, $R$ is the particle radius and $R^{*}$ is the critical radius, corresponding to the particle size which neither shrinks nor grows and which is in equilibrium with a constant concentration of atomic species in the area between the particles (also referred to as the mean-field) at the given time. $\mathrm{R}^{*}$ will increase with time as sintering proceeds and it has been shown that $R^{*}$ equals the mean particle radius ${ }^{10}$.
In the past, the sintering models were mainly evaluated by comparing predictions with experimental observations of ensemble averages or distributions of particle sizes obtained by postmortem characterization ${ }^{3,8,11-17}$. Although this approach has provided significant insight into sintering, deviations of the experimental observations from the model predictions have spurred much debate on the use of indirect observations to unambiguously obtain mechanistic insight ${ }^{12,16,17}$. In this respect, the ensemble-averaged measurements may be beneficially complemented by time-resolved microscopy of the individual nanoparticles using e.g. scanning tunneling microscopy $(\mathrm{STM})^{18-21}$, low energy electron microscopy $(\mathrm{LEEM})^{22}$ or transmission electron microscopy $(\mathrm{TEM})^{23-32}$. Specifically, TEM of oxide-supported nanoparticle catalysts may be performed by a quasi in situ method, in which different or the same areas of a catalyst is monitored repeatedly in-between successive ageing treatments in catalytic reactors $^{3,13,29-32}$, or by an in situ method, in which a specific catalyst area is monitored while the ageing treatment is performed inside the microscope $\mathrm{e}^{23-28}$. 
In the following, we focus on Pt nanoparticles dispersed on an $\mathrm{Al}_{2} \mathrm{O}_{3}$ support. The $\mathrm{Pt} / \mathrm{Al}_{2} \mathrm{O}_{3}$ system represents catalysts for e.g. oxidation reactions in diesel and lean-burn engine exhaust abatement. A net-oxidizing (lean) exhaust composition is characteristic for this type of automotive exhausts ${ }^{33}$. Previous studies suggest that sintering of Pt nanoparticles dispersed on either planar model or porous technical-relevant alumina supports is strongly promoted by the exposure to oxygen at temperatures above ca. $500^{\circ} \mathrm{C}^{3,34}$, but other components of the diesel exhaust such as nitrogen oxides and CO may also affect the catalyst stability ${ }^{35}$ Indirect measurements have been pursued to reveal the dominating oxygen-induced sintering mechanism. For a range of $\mathrm{Pt} / \mathrm{Al}_{2} \mathrm{O}_{3}$ catalyst structures and oxidizing reaction conditions, it is suggested that Ostwald ripening is dominating $^{31,36,37}$ whereas, for Pt particle sizes below 4-5 nm, particle migration and coalescence was suggested to be dominating ${ }^{3,30}$. However, based on in situ observations, Baker et al. found that Pt particles, larger than $2.5 \mathrm{~nm}$, remained stationary during exposure to $2 \mathrm{mbar}^{\mathrm{O}_{2}}$ at temperatures up to $900^{\circ} \mathrm{C}$ and that ripening is dominating ${ }^{24}$. Following the approach by Baker et al, we here present in situ TEM observations of Pt nanoparticles dispersed on a planar $\mathrm{Al}_{2} \mathrm{O}_{3}$ support during exposure to air at elevated temperatures to mimic lean burn conditions. Time-resolved TEM images of the individual nanoparticles unequivocally reveal severe sintering governed by Ostwald ripening. Based on the in situ observations, we present a direct examination of the applicability of equation (1) for predicting the temporal evolution of the particle size distributions and ensemble averages.

\section{Experimental details}

The model catalysts consisting of Pt nanoparticles dispersed on a flat, amorphous $\mathrm{Al}_{2} \mathrm{O}_{3}$ support were prepared on $40 \mathrm{~nm}$ thick, amorphous $\mathrm{Si}_{3} \mathrm{~N}_{4}$ windows supported on $\mathrm{Si}$ wafers to enhance electron transparency (fig. 1a). The flat, amorphous alumina support matches closely a homogeneous medium, which is one of the assumptions of equation (1). Moreover, the uniform support further excludes the inhomogeneous and porous structure of technical support materials that may influence the sintering 
dynamics in ways that are difficult to predict $^{3,34,38}$.
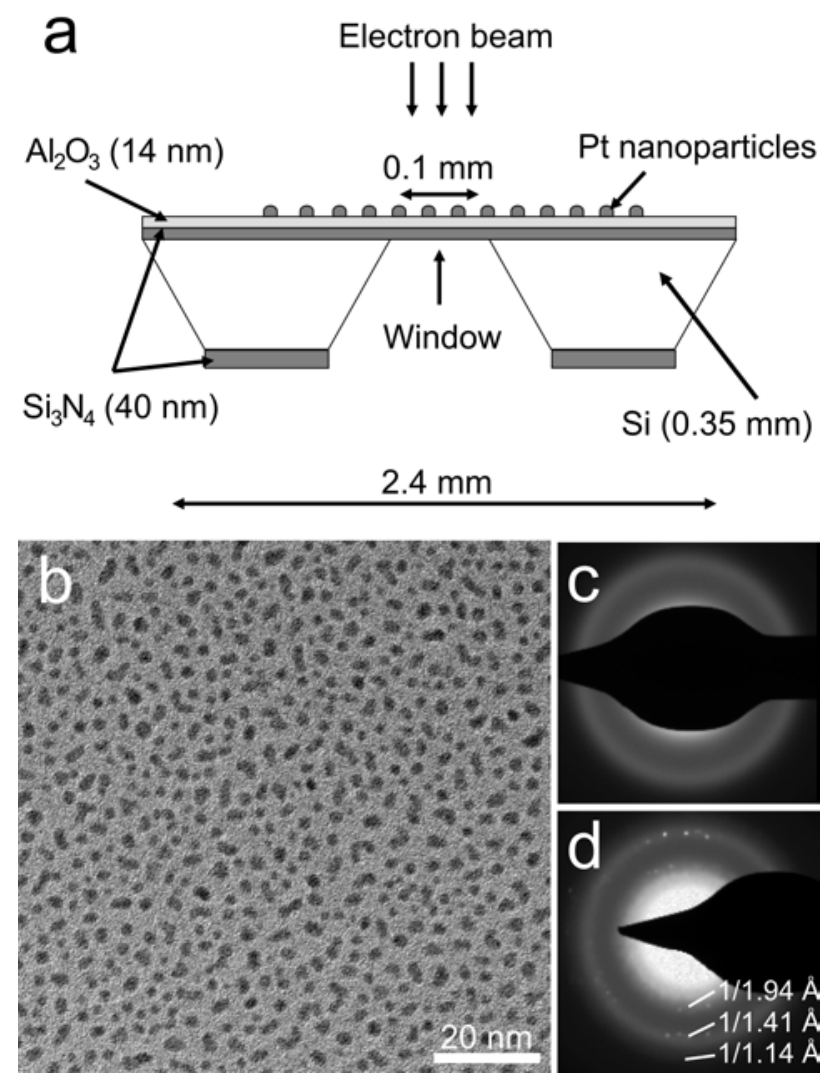

Figure 1. (a) Schematic side-view of the $\mathrm{Pt} / \mathrm{Al}_{2} \mathrm{O}_{3}$ model catalyst. (b) TEM image of the as-prepared $\mathrm{Pt} / \mathrm{Al}_{2} \mathrm{O}_{3}$ model catalyst. (c) Electron diffraction pattern of the bare $\mathrm{Si}_{3} \mathrm{~N}_{4^{-}}$ supported alumina film. (d) Electron diffraction pattern of the model catalyst. Diffraction spots corresponding to the Pt (111), (200) and (220) lattice planes are indicated.

Following the $\mathrm{Si}_{3} \mathrm{~N}_{4}$ window preparation ${ }^{39}$, the specimens were cleaned by oxidation using a microwave plasma processor (TePla 300PC) operated at $250 \mathrm{~W}$ for $2 \mathrm{~min}$. in 1 mbar $\mathrm{O}_{2}$. The $\mathrm{Al}_{2} \mathrm{O}_{3}$ support was formed by physical vapor deposition from an $\mathrm{Al}_{2} \mathrm{O}_{3}$ target of $99.99 \%$ nominal purity (Kurt J. Lesker Company) using an electron beam evaporator (AVAC HVC600)

operated with a base vacuum pressure of $4 \cdot 10^{-6}$ mbar and a deposition rate of $0.05 \mathrm{~nm} / \mathrm{s}$. The resulting $\mathrm{Al}_{2} \mathrm{O}_{3}$ layer has a thickness of ca. $14 \mathrm{~nm}$ measured using ellipsometry, and a root mean square roughness below $0.4 \mathrm{~nm}$ over a $100 \mu \mathrm{m}^{2}$ area determined by atomic force microscopy. Xray photoelectron spectroscopy reveals a characteristic peak at 74,6 eV which corresponds to the table value for the $\mathrm{Al} 2 \mathrm{p} 3 / 2$ peak in pure $\mathrm{Al}_{2} \mathrm{O}_{3}(74,7 \mathrm{eV})$. Furthermore, a selected electron area diffraction patterns of the $\mathrm{Si}_{3} \mathrm{~N}_{4}$-supported alumina layers, obtained using a Titan 80-300 transmission electron microscope (FEI Company), demonstrates only broad and diffuse bands of diffracted electrons consistent with an amorphous structure (fig. 1c). In a final preparation step, platinum was deposited onto the $\mathrm{Al}_{2} \mathrm{O}_{3}$ support layer using the electron beam evaporator (AVAC HVC600) operated with a base vacuum pressure of $4 \cdot 10^{-6}$ mbar. Deposition was done using a Pt target of $99.99 \%$ nominal purity (Nordic High Vacuum AB) with a deposition rate of $0.05 \mathrm{~nm} / \mathrm{s}$ for a nominal $\mathrm{Pt}$ thickness of $0.5 \mathrm{~nm}$. The as-deposited $\mathrm{Pt}$ is 
present as irregularly shaped and crystalline islands with a width of ca. $3 \mathrm{~nm}$ (fig. 1b, d).

X-ray photoelectron spectroscopy reveals ca. $10 \%$ atomic concentration of carbon contamination on the as-prepared catalyst. Based on a previous study of non-catalytic carbon black oxidation $^{40}$, it is most likely that the carbon contamination on the $\mathrm{Pt} / \mathrm{Al}_{2} \mathrm{O}_{3}$ sample will react and/or desorbs during temperature ramping or during the first few minutes at the constant temperature of the experiment in which the sample position stabilized from thermal drift.

In situ TEM experiments were performed using

a CM300 FEG-ST (Philips/FEI Company) electron microscope equipped with a differentially pumped environmental cell $^{41}$. The microscope is operated with a primary electron energy of $300 \mathrm{keV}$ and an ultimate information limit of $0.14 \mathrm{~nm}$ while permitting images or timeelapsed image series to be acquired of samples during the exposure to reactive gases (up to ca. 15 mbar) and elevated temperatures (up to ca. $\left.900^{\circ} \mathrm{C}\right)$. TEM imaging was performed in situ using a $1 \mathrm{k}$ x $1 \mathrm{k}$ Tietz Fastscan F-114 CCD camera, an objective aperture (scattering semiangle of $7.5 \mathrm{mrad}$ ) and at a magnification such that the resulting pixel resolution was $0.26 \mathrm{~nm}$. In the electron microscope, the specimens were exposed to 10 mbar technical air composed of 21 $\% \mathrm{O}_{2}$ and $79 \% \mathrm{~N}_{2}$ (class 2 from Air Liquide). Each specimen exposed to this environment was mounted with the $\mathrm{Pt} / \mathrm{Al}_{2} \mathrm{O}_{3}$ side facing the bottom of the Inconel furnace of a Gatan heating holder (model 628). The holder facilitated the heating of the specimens in the gas environment at a rate of $30^{\circ} \mathrm{C} / \mathrm{min}$. to a temperature in the range 200 $650^{\circ} \mathrm{C}$ where the temperature was kept constant within ca. $3^{\circ} \mathrm{C}$ for up to 6 hours. The temperature was measured using a Pt-Pt/Rh (13 \%) thermocouple spot-welded on the side of the furnace. For temperature calibration, as-prepared specimens were aged either in the microscope or in a thermally equilibrated external tube reactor in 10 mbar technical air at $740^{\circ} \mathrm{C}$ for $3 \mathrm{~h}$. Because the average Pt particle size after heat treatment only differed by $0.5 \%$ for the specimens, the temperature measured on the furnace is concluded to be representative for the specimen temperature in the present experiments.

From the acquired TEM images, Pt particle sizes were measured by manually or automatically outlining the particle perimeters, 
using the software ImageJ, and the corresponding

projected areas of the particles were converted to particle diameters using a circular approximation.

To check the consistency of the automatic approach, images with 1000 particles were automatically and manually analyzed and the best agreement was obtained for an automatic analysis of the images processed by a Gaussian blur filter (Sigma = 3.0), and subsequently, by a Minimum (Radius $=2.0$ pixels) filter. For particles with diameters larger than $2 \mathrm{~nm}$, the error of the particle diameter determined by the automated measurements is approximately $\pm 0.5 \mathrm{~nm}$. A disadvantage of the filter combination is that the sizes of the very small particles (diameter less than $2 \mathrm{~nm}$ ) are overestimated. To circumvent this problem, particles with a diameter smaller than 2 $\mathrm{nm}$ were omitted in the present analysis. In two cases it was necessary to measure diameters below the limit of $2 \mathrm{~nm}$, and in these cases manual measurements were applied (fig. 2 and fig. 4 below). The automatically measured diameters are presented in the form of timeelapsed particle size distributions (PSDs) with an optimum bin size calculated according to ${ }^{42}$. Due to sintering, the optimum bin size changes during the experiment and, as a compromise, the bin size is therefore calculated using the particle size measurements after 3 hours in the in situ experiment.

Before performing the actual experiments it is mandatory to understand and control artifacts that may be induced by the electron beam so that they can be eliminated. The electron beam effects were examined by observing the $\mathrm{Pt} / \mathrm{Al}_{2} \mathrm{O}_{3}$ specimen during the exposure to 10 mbar technical air and at a temperature of $400^{\circ} \mathrm{C}$. Under these conditions, different regions on the specimen were observed, each at a different beam current density below $1 \mathrm{~A} / \mathrm{cm}^{2}$. The regions were initially unexposed to the electron beam and were subsequently imaged with a frame rate of 1.4 frames $/ \mathrm{s}$ (exposure time $=0.5 \mathrm{~s}$ ) for $30 \mathrm{~min}$. The image series revealed two main effects of the electron beam; the shrinkage of the projected $\mathrm{Pt}$ nanoparticle areas and the coalescence of neighboring Pt nanoparticles.

To address the shrinkage, the diameters of 30 Pt nanoparticles were manually measured in the first and last frame of the image series. For particles that eventually disappeared during the $30 \mathrm{~min}$. of exposure to the electron beam, the 
final diameter measurement was obtained from the last frame where the particles were clearly visible, and the shorter beam exposure time was taken into account.

Figure 2a shows a plot of the mean $\mathrm{Pt}$ nanoparticle diameter shrinkage rate versus the electron beam current density and it reveals a linear increase in the diameter shrinkage rate of the Pt nanoparticles with beam current densities increasing up to $1 \mathrm{~A} / \mathrm{cm}^{2}$. The diameter shrinkage was absent in similar experiments conducted in high vacuum $\left(10^{-7}\right.$ mbar $)$ or 10 mbar $\mathrm{N}_{2}$ as well as in the experiments with technical air, but with the electron beam blinded off between the first and last frame (corresponding to a beam current density of $0 \mathrm{~A} / \mathrm{cm}^{2}$ in fig. 2a). Hence, the diameter shrinkage is therefore a combined effect of the electron beam and the oxidizing gas environment.

To address the mechanisms for the apparent loss of $\mathrm{Pt}$, the experiment at $400^{\circ} \mathrm{C}$ and 0.21 $\mathrm{A} / \mathrm{cm}^{2}$ was repeated with a new specimen for a prolonged period of 2 hours. Energy dispersive spectroscopy of the same area on a specimen in its as-prepared state and after the 2 hours exposure to the electron beam revealed a

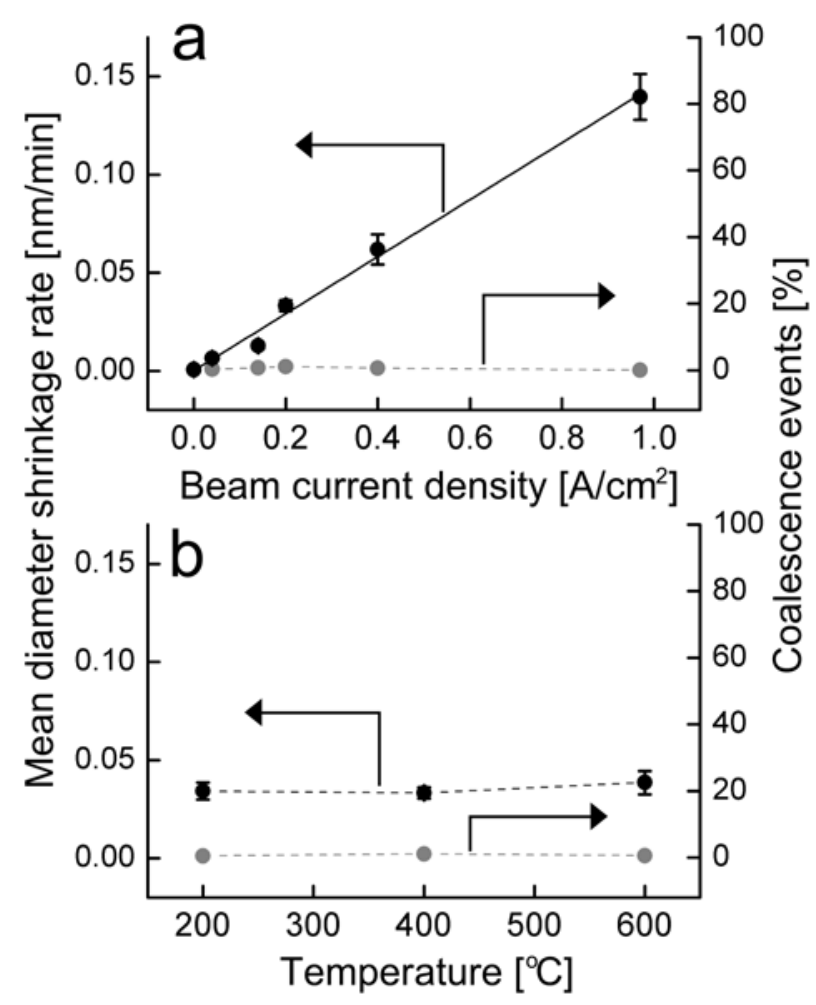

Figure 2. The mean particle diameter shrinkage rate and the number of coalescence events of the $\mathrm{Pt} / \mathrm{Al}_{2} \mathrm{O}_{3}$ catalyst during exposure to 10 mbar air presented (a) as a function of beam current density at constant temperature $\left(400^{\circ} \mathrm{C}\right)$, and (b) as a function of temperature at constant beam current density $\left(0.21 \mathrm{~A} / \mathrm{cm}^{2}\right)$. For each data point, the mean diameter shrinkage rate is based on measurements on 30 particles and the percentage of coalescence events is calculated from more than 400 particles. Error bars refer to the standard deviation of the mean diameter.

loss of Pt as seen from a reduction in the Pt L and M peak intensity. The Pt is probably removed as volatile Pt-oxygen species by the electron beam.

The study of the electron beam effects was repeated to address the influence of temperature variations by using a new specimen exposed to 
the oxidizing conditions at a temperature of $200^{\circ} \mathrm{C}$ and $600^{\circ} \mathrm{C}$. Figure $2 \mathrm{~b}$ shows that the shrinkage was independent of temperature in this interval.

Finally, concerning the coalescence of neighboring Pt particles, only a minor fraction of ca. $1 \%$ of the total number of nanoparticles apparently coalesced in the oxidizing gas environment irrespective of the electron beam current density and temperature (fig. 2a-b). Specifically, the coalescence events involved only particles located in close vicinity with their center of mass separated by ca. $3 \mathrm{~nm}$ and did not involve migration of particles over longer distances. The events could be coalescence events or a localized, fast ripening effect in accordance with ${ }^{43}$. Coalescence events of the type described above were also observed at RT in the high vacuum of $10^{-7}$ mbar in the electron microscope.

The present series of experiments demonstrates the importance of minimizing the electron dose on the specimen in order to quantitatively compare the changes in the ensemble of supported Pt nanoparticles with sintering models with a negligible effect of the electron beam.
Hence, in situ TEM was performed using a low electron beam current density of $0.07 \mathrm{~A} / \mathrm{cm}^{2}$ in order to minimize the effect of the electron beam. Due to the low electron beam current density the noise level increases in the TEM images. To improve the signal to noise ratio as well as to reduce the effect of thermal drift of the specimen in the TEM images, each TEM image presented in the following represents the average of six aligned TEM images recorded successively with an exposure time of $0.5 \mathrm{~s}$ and a frame rate of 1.4 frames/s. For sample regions monitored over the prolonged periods of the in situ experiment, TEM imaging was performed in this way and repeated every $30 \mathrm{~min}$. for 6 hours. In the intervening period, the electron beam was removed from the region. Including time needed for focusing and imaging, the sample regions used in the present analyses were exposed to the electron beam for ca. 1.3 min. per image giving a total exposure time of ca. 17 min. Combined with the measured shrinkage rates (Fig. 2), the total Pt particle diameter shrinkage caused by the electron beam can therefore be estimated to $0.2 \mathrm{~nm}$, which is negligible, compared to the particle sizes. 


\section{Results and discussion}

Sintering of the Pt nanoparticles was activated by heating the model catalyst by $30^{\circ} \mathrm{C} / \mathrm{min}$. up to $650^{\circ} \mathrm{C}$ in an atmosphere of 10 mbar technical air. TEM images were acquired after the establishment of isothermal conditions (corresponding to time $\mathrm{t}=0 \mathrm{~min}$.) and the stabilization of sample drift. In terms of massthickness contrast, the Pt nanoparticles are identified in the TEM images as the darker contrast features which are superimposed at the brighter background that corresponds to the amorphous $\mathrm{Al}_{2} \mathrm{O}_{3}$ support. TEM images acquired 5 min. after the establishment of isothermal conditions showed that the Pt nanoparticles were very similar with respect to size and shape (fig. 3a). Specifically, the treatment resulted in a transformation of the irregular shapes of the asprepared Pt nanoparticles (fig. 1b) to predominantly circular projected shapes (fig. 3a).

A circular projected shape reflects a compact three-dimensional shape consistent with surface energy minimization for a metal nanoparticle. The corresponding distribution of particle diameters (fig. 3f) has an arithmetic mean value of ca. $3 \mathrm{~nm}$ with full width at half maximum of only $1.4 \mathrm{~nm}$. Moreover, in this initial state the particle density was 0.04 particles $/ \mathrm{nm}^{2}$ corresponding to a mean particle-particle separation of ca. $5 \mathrm{~nm}$. The uniform ensemble of Pt nanoparticles prevailed over the entire specimen.

To monitor dynamical changes of the $\mathrm{Pt}$ nanoparticles over the course of time, consecutive TEM images were recorded in situ of the same area of the specimen and played back in the form of a movie (fig. 3a-e, Movie S1). The image series directly reveals that the Pt particles remained immobile during the experiment and that the projected area of the Pt particles either increased or decreased. The observations cannot be due to a morphological transformation of the Pt particles, such as a wetting/non-wetting transformation ${ }^{44}$, because the smaller particles eventually disappear and the larger particles obtain a more pronounced dark contrast, consistent with an increased particle height along the electron beam direction. Hence, the observations directly suggest that sintering of the Pt nanoparticles is governed by an Ostwald ripening mechanism, in agreement with $^{24}$. The corresponding mass-transport is possibly 

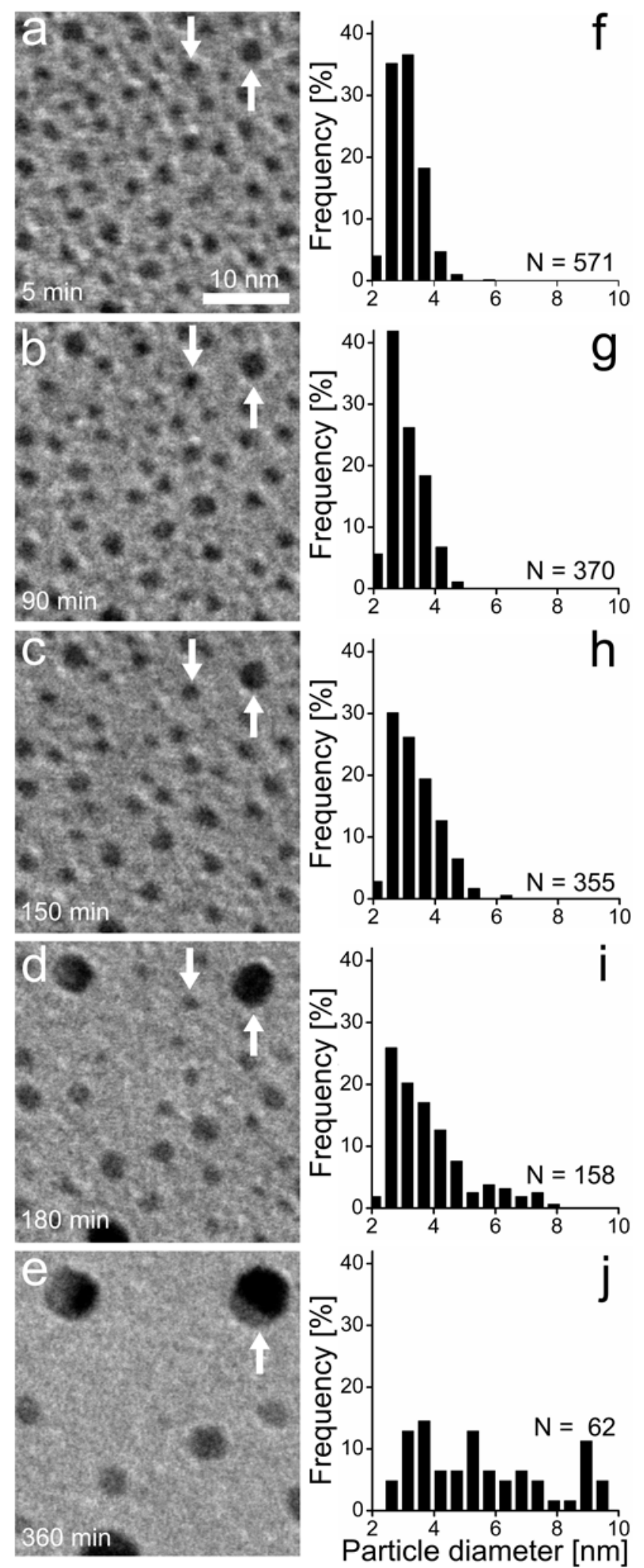

Figure 3. (a-e) Time-lapsed TEM images recorded in situ of the same area of a $\mathrm{Pt} / \mathrm{Al}_{2} \mathrm{O}_{3}$ model catalyst during exposure to 10 mbar air at $650^{\circ} \mathrm{C}$. The images are $40 \times 40$ $\mathrm{nm}^{2}$ sections of TEM images with a full area of $130 \times 130$ $\mathrm{nm}^{2}$. To guide the eye an example of a growing and of a shrinking particle is indicated with arrows. (f-j) presents particles size distributions based on measurements from the full TEM images. $N$ indicates the number of particles included in each particle size distribution.

mediated by Pt atoms, or more likely Pt-oxygen species, since previous studies suggest that the sintering rate of supported Pt nanoparticles in oxidizing environments is accelerated due to the formation of volatile Pt-oxygen species ${ }^{3,35,45}$. The Pt-oxygen species are too small or to fast to be directly detected with the present settings. A similar effect of gas-metal species with enhanced sintering have also been observed in other systems including $\mathrm{H}-\mathrm{Pt}^{46}, \mathrm{~S}-\mathrm{Cu}^{47,48}$ or $\mathrm{OH}-\mathrm{Ni}_{2}{ }^{49}$.

The time-resolved image series provides further insight into the local ripening dynamics of the individual nanoparticles. Figure 4 shows the projected particle diameters in TEM image series for a selection of Pt nanoparticles. In general, the nanoparticles with a large initial diameter tend to grow, while particles with smaller initial diameters tend to shrink over the course of time. Hence the overall dynamics follow the expectation for the Ostwald ripening 


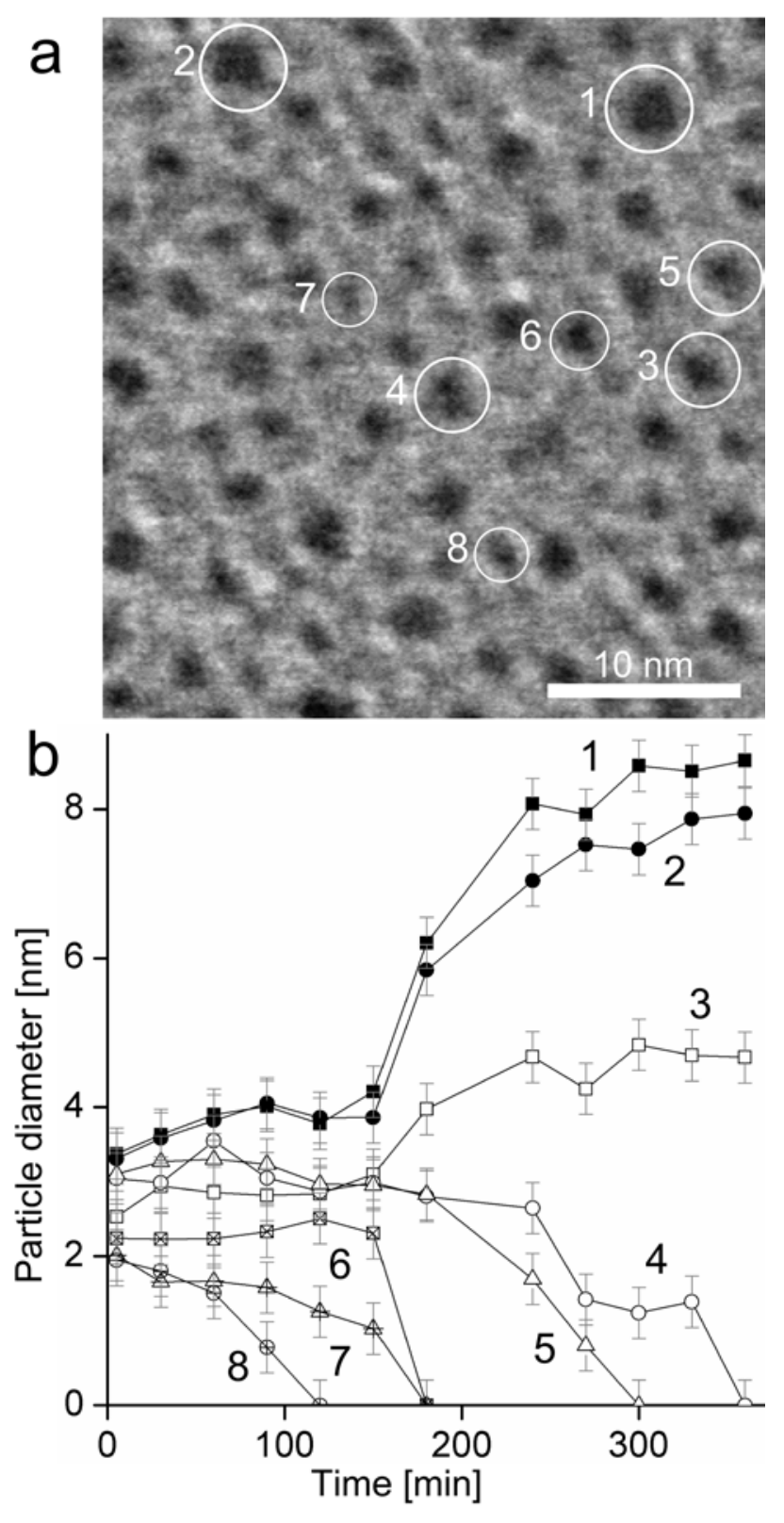

Figure 4. (a) Selection of eight particles in fig. 3a (white circles) for time-resolved analysis. (b) The diameters of the selected particles presented as a function of time. The error bars indicate estimated measuring errors from the manual outlining of the particles.

process $^{8}$. According to mean-field models such as eq. (1), particles with the same size should grow or decay at the same rate. However, a detailed examination of the in situ TEM data in fig. 4 shows discrepancies from the mean-field model. For instance, while the diameter increase of particles 1 and 2 is similar, the diameters of particles 6-8 decay at different rates although the initial diameters are the same. The differences in growth rate are also obvious for particles 3-5.

Similar deviations were previously reported for metal systems under ultra high vacuum and for $\mathrm{Au} / \mathrm{TiO}_{2}$ under $\mathrm{CO}$ oxidation reaction ${ }^{18,21}$. In accordance with those findings, the observations from figure 4 may be attributed to a local effect. That is, the exchange rate of diffusing species for a Pt nanoparticle depends on the size of and the distance to the neighboring nanoparticles rather than on the mean-field concentration established by all nanoparticles. Figure 4 also shows surprisingly that the diameters of most particles are almost stable during the initial stage of the sintering process and that this initial period lasts for up to 2 hours of the experiment. During the initial stage a change in diameter is, however, observed for the smallest particles (Fig. 4). Based on equation (1), it is expected that the rate of diameter change will be highest for the smallest particles. 
The apparent local effects on ripening raise the question whether the mean field model is applicable for describing the ripening kinetics for an entire ensemble of Pt nanoparticles. Figure 3fj presents PSDs derived from particle measurements in the area followed through the experiment (corresponding to fig. 3a-e). Interestingly, the initial Gaussian shape transforms into a skew form as a tail of larger particles emerges on the right side of the mean value and consequently the distribution broadens as a function of time. However, the number of particles in the fixed field of view drops with time. To circumvent the reduced counting statistics, the observations are complemented by a more thorough statistical analysis. This analysis is based on a larger number of TEM images that were acquired during the in situ experiment. At each ageing stage (corresponding to the stages of Fig. 3), several TEM images were acquired at areas on the specimen that were previously not exposed to the electron beam. Figure 5a-e presents examples of TEM images of such different areas and Figure 5f-j presents the PSDs from all the TEM images obtained at a given stage. Qualitatively, fig. 5 reveals changes in the
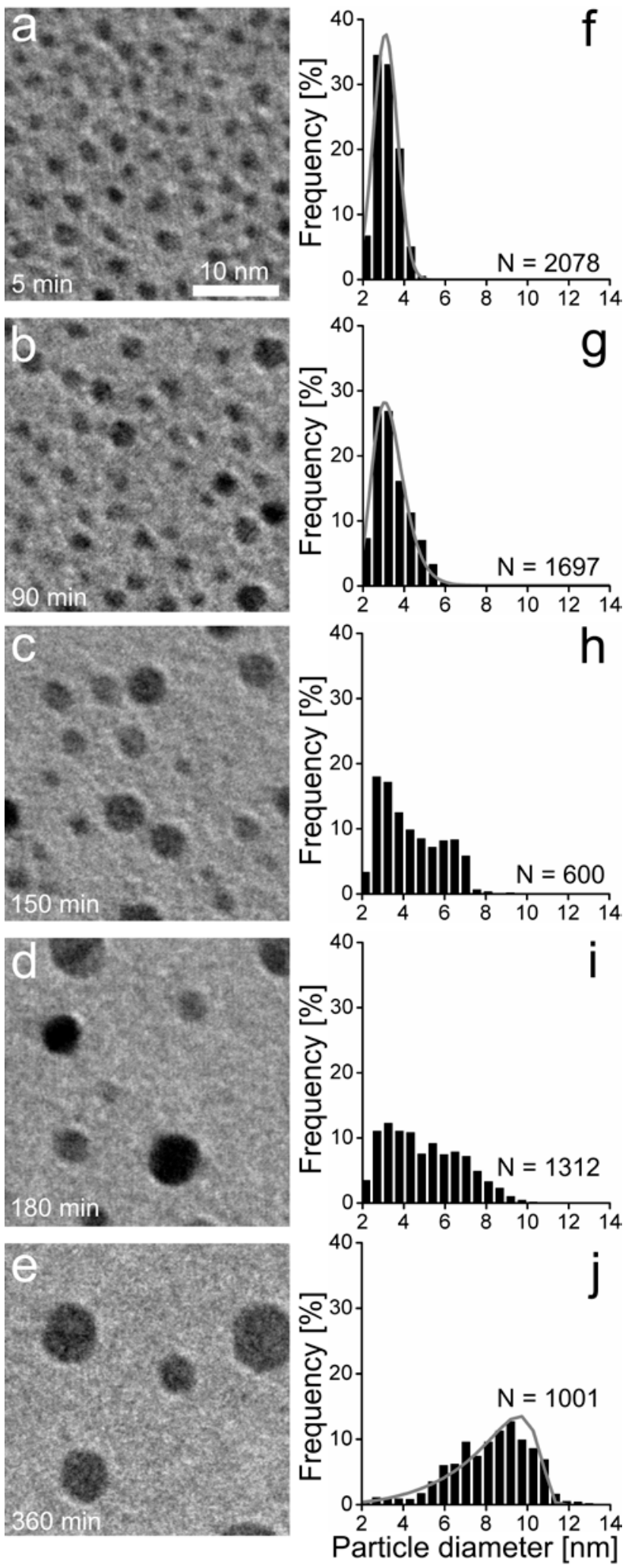

Figure 5. (a-e) TEM images of different randomly chosen areas of a $\mathrm{Pt} / \mathrm{Al}_{2} \mathrm{O}_{3}$ model catalyst during exposure to 10 mbar air at $650^{\circ} \mathrm{C}$. The images are $40 \times 40 \mathrm{~nm}^{2}$ sections of TEM images with a full area of $130 \times 130 \mathrm{~nm}^{2}$. (f-j) presents PSDs based on measurements from a number 
of TEM images of areas previously unexposed to the electron beam. A (f) Gaussian, (g) lognormal and (j) twodimensional LSW distribution is fitted to the data ${ }^{52} . N$ indicates the number of particles included in each particle size distribution.

Pt nanoparticle sizes similar to the observations in fig. 3. The improved statistical material, however, results in more well-defined PSD shapes. Specifically the initial shape is approximately Gaussian (fig. 5f). At later stages the PSD is fitted better with a log-normal distribution (fig. 5g) as larger particles form at the expense of the smaller particles. Eventually the distribution peaks to the left of its mean value (fig. 5j), and at this stage the distribution is fitted well with the so-called Lifshitz-Slyozov-Wagner (LSW) model ${ }^{50,51}$ modified to represent a twodimensional system ${ }^{52}$.

The LSW model was previously established to describe Ostwald ripening mediated sintering ${ }^{50,51}$, but the distinct LSW shaped PSD has not previously been reported on technical catalysts. Even after severe ageing in oxygen at ambient pressures, lognormal like shapes are typical for PSDs of technical catalysts ${ }^{16}$. It has been discussed that the sintering mechanism may be deduced from the specific shapes of the particle size distributions ${ }^{3,8,11,12}$. However, Datye et al. argued recently, based on indirect post-mortem examinations of technical relevant catalysts, that it indeed is difficult to infer the mechanism from the particle size distributions ${ }^{16}$. In line with this work, the present findings reveal that such attempts are not straightforward because the PSD may expose a time-dependency and that a transitional period may exist, in which one specific sintering mechanism results in several different shapes of the PSD. A possible explanation for why the LSW shape is found in this study in contrast to studies on technical catalysts is that the present uniform support and homogeneous initial distribution of the $\mathrm{Pt}$ nanoparticles resemble the assumptions underlying the LSW model closer than the inhomogeneous support structure and nanoparticle distribution of technical catalysts.

Based on the PSDs, the temporal evolution of ensemble-averaged properties, such as the number-averaged mean particle diameter and particle density, is determined (fig. 6a-b). Figure 6a shows that the overall trend of change in the mean diameter with ageing time is similar for the 


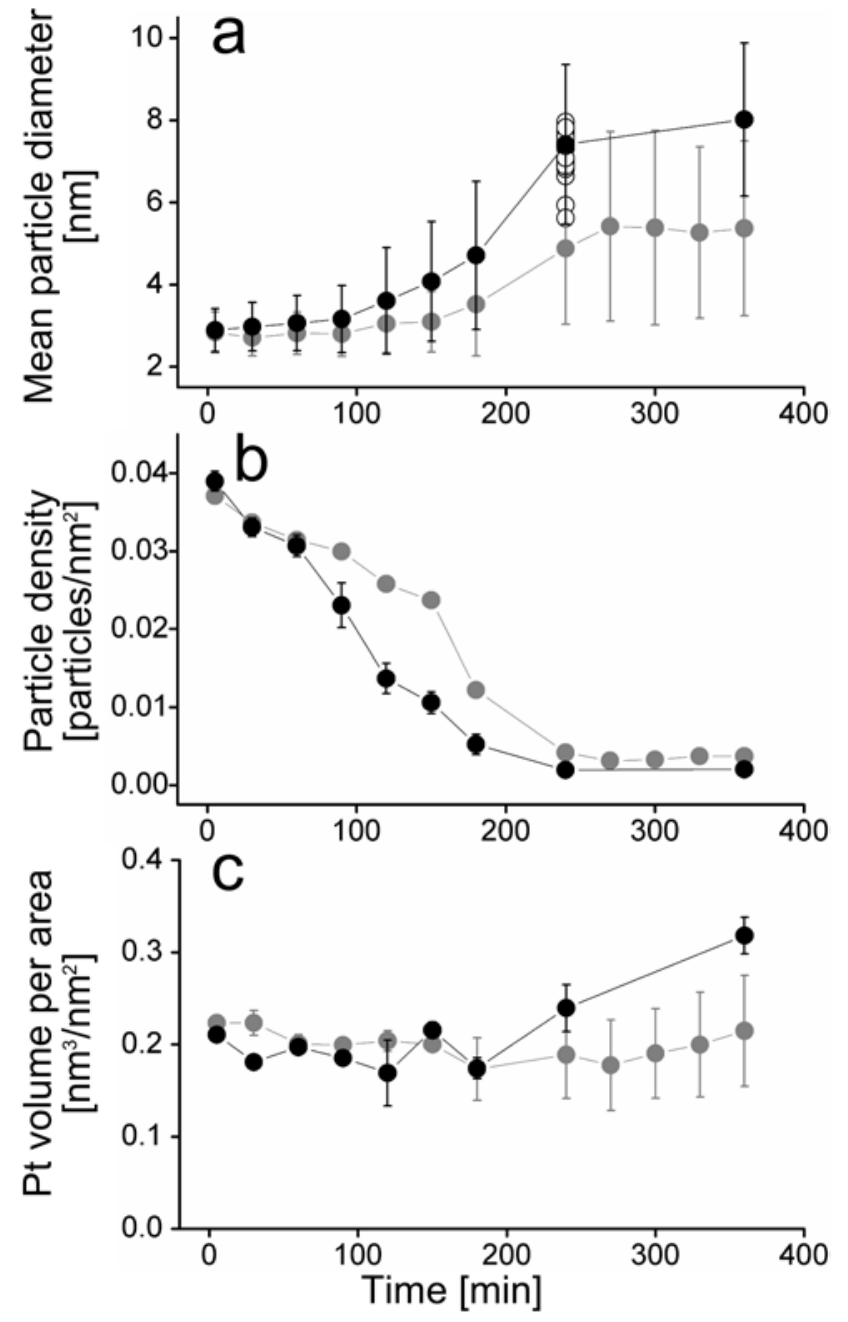

Figure 6. (a) Mean particle diameter, (b) particle density and (c) Pt volume per support area as a function of aging time for particles in an area followed over time, corresponding to figure 3 (grey) and for areas previously unexposed to the electron beam, corresponding to figure 5 (black). In (a-b) error bars refer to the standard deviation of the particle diameters and density respectively. In (c) error bars refer to the propagated measuring error. In (a) an example of the statistical spread in mean particle diameter for different areas on the specimen is presented with open circles at $240 \mathrm{~min}$. limited area (corresponding to fig. 3) and the additional areas (corresponding to fig. 5). The mean diameter remains almost stable during the initial period, but suddenly increases rapidly and subsequently becomes roughly constant with time. The error bars in fig. 6a show how the standard deviation of the particle sizes changes with time as well. Initially, the standard deviation is small reflecting a narrow initial PSD. The spread in particle sizes increases at the onset of the fast increase in the mean particle diameter. Finally both the mean diameter and the particle spread remain almost constant. Figure 6b shows that the particle density is high during the initial stage and is reduced with time until it stabilizes when the mean diameter stabilizes (fig. 6a-b). The results in figures $6 \mathrm{a}$ and $\mathrm{b}$ clearly show that the sintering rate slows down in the final sintering stage. That the mean diameter is almost stable in the initial stage (fig 6a) could indicate that no sintering is taking place at this stage. However, the decrease in density shows that particles decay and that a slow sintering process indeed proceeds (6b). This is also consistent with figure $4 \mathrm{~b}$ which shows that the smallest particle diameters appear to shrink over time. 
Although the data sets presented in fig. 6a-b reflect the same overall trend, differences are also apparent. Based on the consideration of electron beam-induced shrinkage (fig. 2), the difference is likely not dominated by such effects. It can not be ruled out that the difference partly results from removal of free diffusing Pt-oxygen species from the specimen by the electron beam. However, the volume of $\mathrm{Pt}$ in the nanoparticles can be estimated using a hemispherical shape approximation to the projected $\mathrm{Pt}$ particles outlined in the TEM images. Figure 6c shows that the Pt volume is stable throughout most of the experiment and does not reflect a significant loss of Pt, but rather a slight increase in the end. Because $\mathrm{Pt}$ is not added to the sample, the apparent volume increase indicates that the particle shape changes to obtain a slightly larger projected area and that the hemispherical shape assumption is too simple. Hence the results in figure 6c can only be taken as indicative. It is noted that the mean particle diameter obtained from single TEM images of different areas indeed varies as indicated (fig. 6a, open circles) and this intrinsic spread is likely the reason for the discrepancy between the particle size averaged over a single area and multiple areas.

To address the question whether the observed temporal evolution of the PSDs, as well as the mean particle diameter and particle density reflect the Ostwald ripening characteristics, the observations are compared to simulations based on equation (1). The simulations follow the procedure of Smet et. al. ${ }^{53}$ with discrete time steps of $0.5 \mathrm{~min}$. and using an initial Gaussian distribution with a particle number and an initial particle density corresponding to the PSD in figure $5 f$. The simulations are performed in an iterative way by varying a constant corresponding to $\alpha$ of equation (1), until the particle density of the simulated distribution fits the observed particle density of figure 5 best for all times. These simulations produce the PSDs presented in fig. 7a, the mean particle diameter (black line) presented in fig. 7b and the particle density (black line) presented in fig. 7c. In another simulation run, the simulation constant was tuned to obtain the best match with the mean particle diameter of figure 5 . The simulated mean particle diameter and corresponding density are shown as the grey curves in figure $7 \mathrm{~b}$, c. 

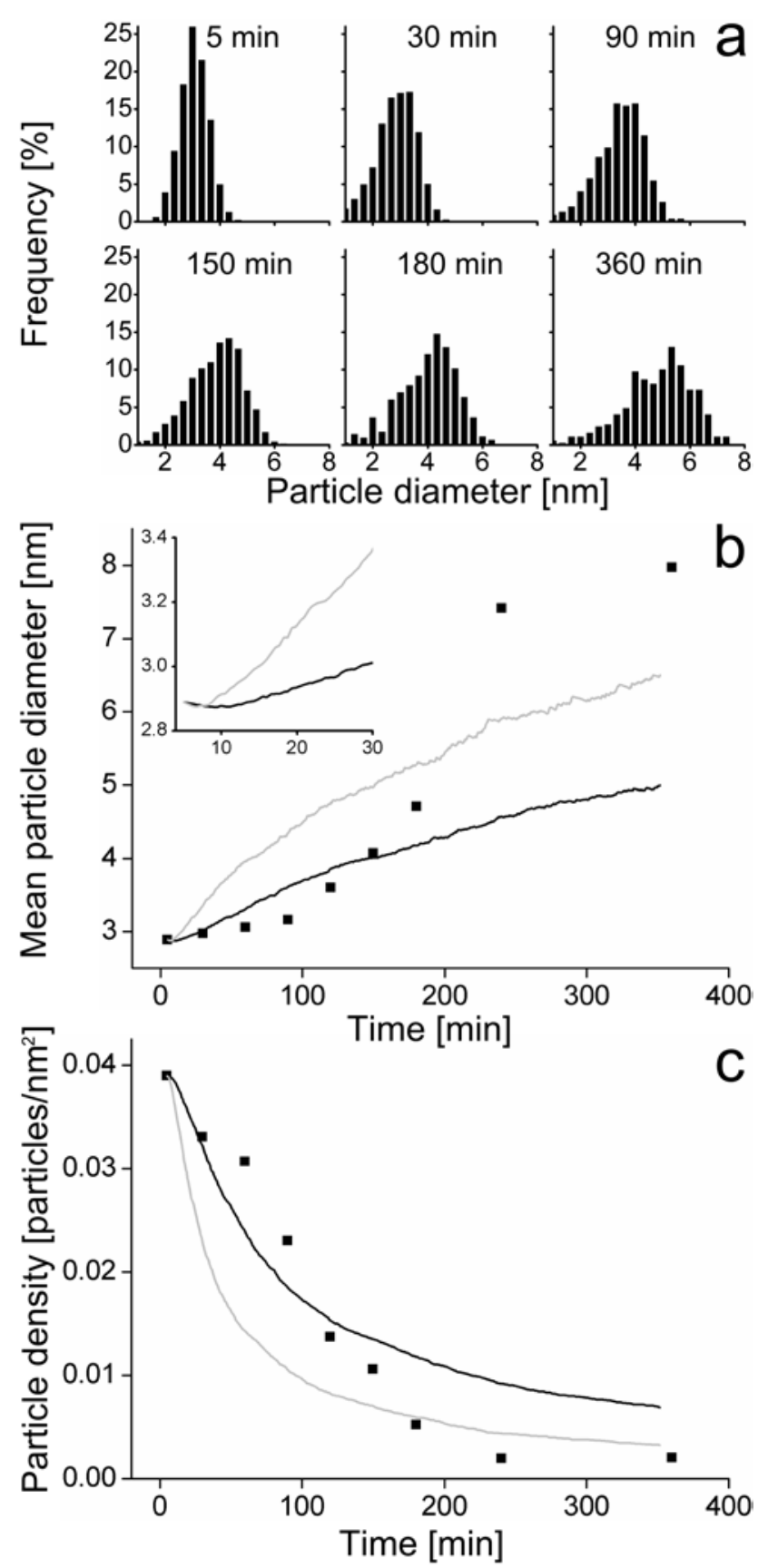

Figure 7. Simulations of the time evolved particle size distribution (a), mean particle diameter (b) and the particle density (c) following ${ }^{53}$. The initial particle size distribution used for the simulation is a Gaussian distribution with mean and width corresponding to the distribution in figure $5 f$. Experimental measurements of the mean particle diameter and density corresponding to figure 6a-b are included (squares). For (b) and (c) the parameters of the simulation is set to get the best possible agreement with the observed mean diameter (grey) or particle density (black). To guide the eye a zoom on the first $30 \mathrm{~min}$. is inserted in (b).

The simulated PSDs as a function of time shows that the initial Gaussian shape transforms into a LSW shape over time. The simulated enddistribution matches the experimentally observed PSD (fig. 5j). However, while the simulations indicate a gradual change of the initial Gaussian distribution into the LSW shape, the experimentally observed distributions show transitional shapes with a tendency for a tail to the right of their maximum until the LSW shape emerges. The difference may reflect inherent scatting of the experimental data or the shortcomings of the model that are discussed below.

The simulated mean particle diameter evolves in time with an initial almost stationary period, followed by a rapid increase and, subsequently, by a period of slower growth (fig. 7b). The simulated particle density evolves with an initial fast decrease that then slows down. The trends in the time-evolution of the mean particle diameter have previously been reported for simulations based on narrow Gaussian initial PSDs ${ }^{8,53}$. There appears to be overall qualitatively agreement between the simulated and the experimental data 
for time-dependency of the mean particle diameter and particle density whereas quantitative differences are apparent. Specifically, both the simulations and the experiment show interestingly that the initial stage with slow sintering is correlated with a narrow PSD. One explanation for the coupling of slow sintering with a narrow PSD is that even though a concentration of atomic species is believed to be generated from the initially small particles, larger particles are needed to take up the atomic species according to the GibbsTompson effect. This, in turn, means that a broadening of the PSD will increase the sintering rate. This result also suggests that one route to suppress the deactivation of industrial catalysts through sintering could be to aim for very narrow initial PSDs. This will not be a route for stabilizing the catalysts, but may be a route for prolonging the meta-stable initial state resulting in higher total activity. In comparison, a slow onset for $\mathrm{S}$ induced ripening of $\mathrm{Cu}$ is also previously reported, but attributed to a shift in S concentration $^{48}$.

The differences between the simulated and observed time-dependencies of the mean particle diameter and particle density include several effects. First, the initial period with a stationary mean particle size and narrow particle size distribution is considerably shorter for the simulated (ca. $10 \mathrm{~min}$.) than for the experimental data (ca. 2 hours). The longer stationary period in the experiment could possibly be an additional kinetic effect related to the establishment of the concentration of Pt-oxide complexes on the support or the difference in Pt particle size that are governing the ripening process. Second, the experimental observations show final mean particle sizes and particle densities that are larger and smaller, respectively, as compared to the simulated parameters. It should also be noted that although the present model systems was generated to match closely the assumptions underlying the model (eq. 1), the experimental situation still may deviate from the model assumptions. Because the particles are imaged in a projection orthogonal to the support surface, the projected particle diameter represents only a simple measure for the $\mathrm{Pt}$ morphology. The particle shape is determined by the surface free energies of the exposed Pt surface sites and by the Pt-alumina interface energy. As the nature of 
the surface sites may change with $\operatorname{size}^{54}$ and oxygen adsorption is site-dependent ${ }^{55,56}$, the oxygen atmosphere may affect the surface free energy and hence particle shapes in a sizedependent way. Moreover, as surface defects could act as anchor sites (as suggested for Pt on gamma-alumina ${ }^{57}$ ) the interface energy may also be speculated to be partly inhomogeneous. In such a case the adhesion of the Pt particles with different size could vary and thus also affect the Pt morphology. Furthermore, it is noted that the used model assumes that the concentration of atomic species around the particles is described by the Gibbs-Thompson equation and that the concentration increases to the mean-field value, which pertains in the area between the immobile particles $^{3}$. However, the high initial fractional $\mathrm{Pt}$ coverage and a small mean Pt particle separation of ca. $5 \mathrm{~nm}$ may cause a breakdown of the meanfield approximation because of overlap in concentration gradients of the atomic species surrounding the particles. The particles may therefore directly affect their neighbor's growth rates, rather than indirectly through the mean field concentration of mass-transporting species. The direct interaction with neighbor particles could explain the local deviations from the mean field model as observed in fig. 4. Moreover, a local overlap of the concentration gradient can be imagined to affect the time-dependency of the changes in the whole ensemble of $\mathrm{Pt}$ nanoparticles, as addressed by Dadyburjor et $\mathrm{al}^{58}$, and hence cause deviations in particle size distributions, average particle size as well as particle density from the mean field model predictions as reflected in fig. 7.

\section{Conclusion}

In situ TEM is used to monitor Pt nanoparticles dispersed on a planar, amorphous $\mathrm{Al}_{2} \mathrm{O}_{3}$ support during exposure to 10 mbar of synthetic air at $650^{\circ} \mathrm{C}$. Time-resolved image series unequivocally reveal that $\mathrm{Pt}$ nanoparticle sintering is mediated by an Ostwald ripening process and allow for a direct comparison to the mean-field model for Ostwald ripening. A statistical analysis of an ensemble of $\mathrm{Pt}$ nanoparticles shows that the particle size distributions change shape as a function of time. Specifically, the particle size distribution changes from an initial Gaussian distribution via a lognormal type distribution to a LSW distribution 
under the present sintering conditions. Furthermore, the overall trends of the timedependency of the ensemble-averaged particle size and particle density agree with the meanfield expectations. However, at the individual nanoparticle level discrepancies are observed suggesting that the local environment influences the atom exchange process.

Acknowledgment. We gratefully acknowledge Bengt Kasemo, Jonas Andersson, Elin Larsson and Laurent Feuz (Chemical Physics Group) as well as Eva Olsson (Microscopy and Microanalysis Group) at Chalmers University of Technology for contributing to sample preparations. We thank the MC2-Access project for financial support. We acknowledge the participation of the CTCI Foundation, Taiwan, in the establishment of the in situ TEM facility at Haldor Topsøe A/S. CINF is funded by The Danish National Research Foundation.

\section{Supporting Information Available. Movie S1}

shows the time-elapsed in situ TEM images of the $\mathrm{Pt} / \mathrm{Al}_{2} \mathrm{O}_{3}$ model catalyst during exposure to 10 mbar air at $650^{\circ} \mathrm{C}$. The acquisition time relative to the time of reaching the temperature $650^{\circ} \mathrm{C}$ is given for each frame. S1 shows the full $130 \times 130 \mathrm{~nm}^{2}$ area corresponding to figure 3a-e. This information is available free of charge via the Internet at http://pubs.acs.org/

\section{References}

1 Somorjai, G. A.; Frei, H.; Park, J. Y. J. Am. Chem. Soc. 2009, 131, 16589

2 Bell, A. T. Science, 2003, 299, 1688

3 Wynblatt, P.; Gjostein, N. A. Prog. Solid State Ch. 1976, 9, 21

4 Bartholomew, C. H. Stud. Surf. Sci. Catal. 1997, 111, 585

5 Fuentes, G. A.; Salinas-Rodriguez, E. In Catalyst Deactivation; Bartholomew, C. H. Ed.; Fuentes, G. A. Ed.; Elsevier Science B.V: Amsterdam, 1999; 573-584

6 Campbell; C. T. Surf. Sci. Rep. 1997, 227, 1

7 Chakraverty, B. K. J. Phys. Chem. Solids 1967, 28, 2401

8 Flynn, P. C.; Wanke, S. E. J. Catal. 1974 34,400 
9 Coughlan, S. D.; Fortes, M. A. Scripta

Metallugica et Materialia 1993, 28, 1471

10 Finsy, R. Langmuir 2004, 20, 2975

11 Ruckenstein, E.; Pulvermacher, B. J. Catal 1973, 29, 224

12 Granqvist, C. G.; Buhrman, R. A. J. Catal. 1976, 42, 477

13 Harris, P. J. F. Int. mat. Rev. 1995, 40, 97

14 Campbell, C. T.; Parker, S. C.; Starr, D.

E. Science 2002, 298, 811

15 Sehested, J.; Gelten, J. A. P.; Remediakis,

I. N.; Bengaard, H.; Nørskov, J. K. J. Catal. 2004, 223, 432

16 Datye, A. K.; Xu, Q.; Kharas, K. C.;

McCarty, J. M. Catalysis Today 2006, 111, 59

17 Wanke, S. E. J. Catal., 1977, 46, 234

18 Morgenstern, K.; Rosenfeld, G.; Comsa, G. Surface Science 1999, 441, 289

19 Linderoth, T. R.; Horch, S.; Petersen, L.;

Helveg, S.; Lægsgaard, E.; Steensgaard, I.;

Besenbacher, F. Phys. Rev. Lett. 1999, 82, 1494
20 Jak, M. J. J.; Konstapel, C.; Kreuningen,

A. van; Verhoeven, J.; Frenken, J. W. M. Surface Science 2000, 457, 295

21 Yang, F.; Chen, M. S.; Goodman, D. W. J. Phys. Chem. C 2009, 113, 254

22 Theis, W.; Bartelt, N. C.; Tromp, R. M. Phys. Rev. Lett. 1995, 75, 3328

23 Baker, R. T. K.; Harris, P. S.; Thomas, P. B. Surface Science 1974, 46, 311

24 Baker, R. T. K.; Thomas, C.; Thomas, R. B. J. Catal. 1975, 38, 510

25 Heinemann, K.; Poppa, H. Thin Solid Films 1976, 33, 237

26 Anton, R.; Kreutzer, P. Phys. Rev. B. 2000, 61, 16077

27 Liu, R. J.; Crozier, P. A.; Smith, C. M.; Hucul, D. A.; Blackson, J.; Salaita, G. Appl. Catal. A-Gen. 2005, 282, 111

28 Hannon, J. B.; Kodambaka, S.; Ross, F. M.; Tromp, R. M. Nature 2006, 440, 69

29 Sushumna, I.; Ruckenstein, E, J. Catal. 1988 109, 433 
30 Harris, P. J. F.; Boyes, E. D.; Cairns, J. A.

J. Catal. 1983, 82, 127

31 Bartholemew, C. H. Catalysis - A Specialist Periodical Report, volume 10; The Royal Society of Chemistry: Cambridge, 1993; 41-82.

32 Bellare, A.; Dadyburjor, D. B.; Kelly, M. J. J. Catal. 1989, 117, 78,

33 Twigg, M. V. Appl. Catal B 2007, 70, 2

34 Wanke, S. E.; Flynn, P. C. Catal. Rev. Sci. Eng. 1975, 12, 93

35 Lööf, P.; Stenbom, B.; Nordén, H.;

Kasemo, B. J. Catal. 1993, 144, 60

36 Lee, T. J.; Kim, Y. G. J. Catal. 1984, 90, 279

37 Rickard, J. M.; Genovese, L.; Moata, A.; Nitsche, S. J. Catal. 1990, 121, 141

38 Ahn, T. M.; Tien, J. K.; Wynblatt, P. J. Catal. 1980, 66, 335

39 Grant, A. W.; Hu, Q.-H.; Kasemo, B. Nanotechnology 2004, 15, 1175
40 Simonsen, S. B.; Dahl, S.; Johnson, E.; Helveg, S. J. Catal. 2008, 255, 1

41 Hansen, P. L.; Datye, A. K.; Helveg, S. Adv. Catal. 2006, 50, 77.

42 Freedman, D.; Diaconis, P. Z Wahrscheinlichkeit 1981, 57, 453

43 Yang, W. C.; Zeman, M.; Ade, H.; Nemanich, R. J. PRL 2003, 90, 136102

44 Hansen, P. L.; Wagner, J. B.; Helveg, S.; Rostrup-Nielsen, J. R.; Clausen, B. S.; Topsøe, H. Science 2002, 295, 2053

45 Chaston, J. C. Platinum Metals Rev. 1966, 10, 91

46 Horch, S.; Lorensen, H. T.; Helveg, S.; Lægsgaard, E.; Stensgaard, I.; Jacobsen, K. W.; Nørskov, J. K.; Besenbacher, F. Nature 1999, 398, 134

47 Feibelman, P. J. PRL 2000, 85, 606

48 Ling, W. L.; Bartelt, N. C.; Pohl, K.; Figuera, J.; Hwang, R. Q.; McCarty, K. F. PRL 2004, 93, 166101

49 Sehested, J. J Catal. 2003, 217, 417 
50 Lifshitz, I. M.; Slyozov, V. V. J. Phys. 55 Wand, L.; Roudgar, A.; Eikerling, M. J. Chem. Solids 1961, 19, 35.

Phys. Chem. C 2009, 113, 17989

51 Wagner, C. Z. Elektrochemie 1961, 65, 56 Sljivancanin, Z.; Hammer, B.; Surf. Sci. 581 2002, 515, 235

52 Rogers, T. M.; Desai, R. C.; PRB 1989 57 Kwak, J. H.; Hu, J.; Mei, D.; Yi, C.-W.; 39, 11956

Kim, D. H.; Peden, C. H. F.; Allard, L. F.; Szanyi, J. Science 2009, 325,1670

53 Smet, Y. D.; Deriemaeker, L.; Finsy, R. 58 Dadyburjor, D. B.; Marsh, S. P.; Langmuir 1997, 13, 6884 Glicksman, M. E. J. Catal. 1986, 99, 358

54 Hardeveld, R.; Hartog, F.; Surf. Sci. 1969, 15, 189 
TOC:

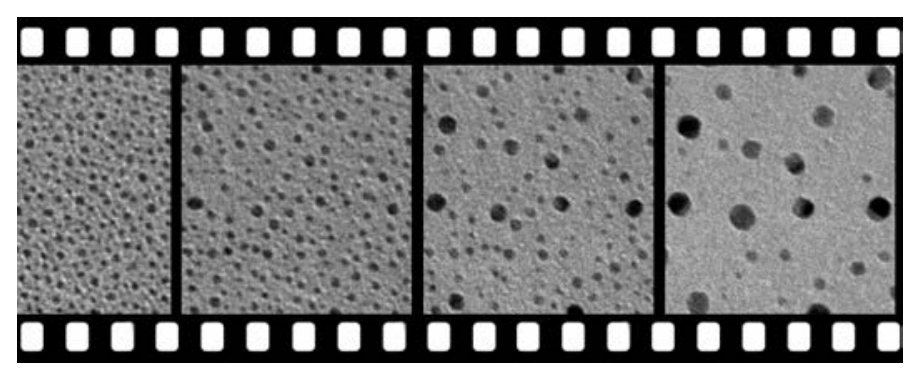

